\title{
MARX E A VIGÊNCIA CONTEMPORÂNEA DA RACIONALIDADE CAPITALISTA
}

\author{
Edilson José Graciolli
}

RESUMO: A partir da problematização levantada pela tese de que o trabalho não seria, hoje, mais a atividade central na formação social capitalista, o artigo pretende examinar a pertinência da categoria trabalbo social, tal qual se encontra no pensamento de Marx, com vistas a sustentar, de um lado, o caráter ineliminável do trabalho concreto, enquanto processo que produz valores-de-uso, e, de outro, a vigência contemporânea da lógica do trabalho abstrato.

UNITERMOS: Capitalismo; Sociologia Industrial; Trabalhadores.

O objetivo do presente artigo é examinar a tese do fim da centralidade do trabalho nas sociedades contemporâneas à luz do conceito trabalho social em Marx, do ponto de vista da sua pertinência mesmo no atual padrão de acumulação do capital, cujos traços distinguidores se encontram em torno do patamar tecnológico (articulado a partir das profundas inovações na microeletrônica, microbiologia e esfera energética), de processos de flexibilização na produção, no consumo e no gerenciamento da força de trabalho e, inclusive, do redimensionamento da divisão internacional do trabalho ${ }^{1}$.

${ }^{1}$ A bibliografia atinente é vasta. Dentro da abordagem crítica da qual pretendemos 
A tese em questão é, além de significativamente aceita nos meios acadêmicos, por assim dizer, "legitimada" por autores importantes, notadamente por Gorz, Offe e Habermas. Por sua capacidade de sintetizar a argumentação, Habermas é referência básica para tal tese, razão pela qual o citaremos. Para ele,

"... chegou ao fim uma determinada itopia que, no passado, cristalizou-se em torno do potencial de uma sociedade do trabalho (...) Acima de tudo, a utopia perdeu seu ponto de referencia na realidade: a força estruturadora e socializadora do trabalho abstrato (...). Desde a metade dos anos 70 os limites do projeto do Estado social ficam evidentes, sem que até agora uma alternativa clara seja reconbecivel. Em razão disso, gostaria de precisar minha tese: a nova ininteligibilidade é própria de uma situação na qual um programa de Estado social, que se nutre reiteradamente da utopia de uma sociedade do trabalho, perdeu a capacidade de abrir possibilidades futuras de uma vida coletivamente melhor e menos ameaģada" $(1987$, p.105106) $)^{2}$.

obter elementos para a análise que segue, destacamos SCHAFF, A., A Sociedade Informática, São Paulo, Brasiliense/Unesp, 1990; KATZ, C., Novas Tecnologias - crítica da atual reestruturação produtiva, São Paulo, Xamãa, 1995; LOJKINE, J., Revolução Informacional, São Paulo, Cortez, 1995; LOJKINE, J., $A$ classe operária em mutacóes, São Paulo, Oficina de Livros, 1990; HARVEY, D., A Condigão Pós-Moderna, São Paulo, Ed. Loyola, 1992; OLIVEIRA, Carlos Alonso Barbosa de \& outros (orgs.), Mundo do Trabalho - crise e mudança no final do século, São Paulo, Ed. Página Aberta, 1994; IANNI, O., Teorias da Globalizagáão, Rio de Janeiro, Civilização Brasileira, 1995.

${ }^{2} \mathrm{O}$ debate sobre a perda ou não da centralidade da categoria trabalho nas sociedades contemporâneas é intenso. Conferir, a respeito, ANTUNES, R., Adeus ao Trabalho?, São Paulo/Cortez; Campinas/Ed. Unicamp, 1995; MAAR, W. L., "Fim da sociedade do trabalho ou emancipação crítica do trabalho social?", In: Vários autores, Liberalismo e Socialismo: velhos e novos paradigmas, São Paulo, Ed. da Unesp, 1995; GORZ, A., Adeus ao Proletariado, Rio de Janeiro, Forense, 1982; KURZ, R., O Colapso da Modernizagão - da 
Há, evidentemente, uma identificação, operada por Habermas, entre centralidade do trabalho e centralidade do trabalho abstrato. Em termos marxianos, diríamos que Habermas universaliza a formação social centrada no trabalho abstrato, como se mudanças nessa maneira particular de organizar $\mathrm{o}$ trabalho social repercutissem, direta e necessariamente, no trabalho enquanto atividade social em toda e qualquer sociedade, existente ou que possa vir a existir.

O resgate - não pelo argumento da autoridade, mas pela capacidade de desvendar nexos, de lograr intelecção, acerca da sociedade capitalista contemporânea - do conceito marxiano de trabalbo social é imprescindível à correta avaliação sobre a perda ou não da centralidade do trabalho.

$\boldsymbol{O}$ trabalho não existe. Ele é sempre social, vale dizer, efetiva-se no interior de relações sociais específicas. Ao analisar a fórmula trinitária (capitallucro; terra-renda fundiária; trabalho-salário), Marx diz o seguinte sobre a pretensão de se conceber a forma social capitalista de organizar o trabalho como a única possível, ou mesmo de se enfocar o processo de intercâmbio entre o homem e a natureza sem considerá-lo socialmente:

"E, por fim, como terceiro elemento nessa união, um mero fantasma: 'o' trabalbo, que não é nada mais que uma abstração e, considerado em si, nem sequer existe ou, se considerarmos o que se pretende dizer a atividade produtiva do ser bumano genericamente, mediante a qual ele intermedia o metabolismo com a natureza, despojada não só de toda forma social e de toda determinação social do caráter, mas mesmo em sua mera existência natural, independente da sociedade, desligada de todas as sociedades e como exteriorização e afirmação da vida comuns ao

derrocada do socialismo de caserna à crise da economia mundial, São Paulo, Paz e Terra, 1992; OFFE, C., Trabalho como Categoria Sociológica Fundamental?, Trabalho \& Sociedade, Rio de Janeiro, Tempo Brasileiro, vol. I; SILVA, J.P., Trabalho e Teoria Social: Habermas, Gorz e o conceito de sociedade dual, Idéias, Campinas, n. 2, Gráfica do IFCH/UNICAMP, julho/dezembro de 1995. 
bomem, que ainda não é, no entanto, social e ao homem socialmente determinado de algum modo" (1986, p.270).

Deve-se entender o qualitativo social tanto pela cooperação entre indivíduos que o trabalho implica, quanto por designar um processo que ocorre em um quadro de relações sociais específicas, determinadas, datadas historicamente e que, por isto mesmo, não podem ser eternizadas:

\begin{abstract}
"... o processo de produção capitalista é uma forma bistoricamente determinada do processo social de produção em geral. Este último é tanto processo de produção das condições materiais de existência da vida bumana quanto processo que, ocorrendo em relações bistóricoeconômicas de produção específicas, produz e reproduz essas mesmas relações de produção e, com isso, os portadores desse processo, suas condições materiais de existência e suas relações recíprocas, isto é, sua forma sócio-econômica determinada. Pois a totalidade dessas relações, em que os portadores dessa produção se encontram com a Natureza e entre si, em que eles produzem, essa totalidade é exatamente a sociedade, considerada segundo sua estrutura econômica. Como todos os seus predecessores, o processo de produção capitalista transcorre sob determinadas condições materiais que, no entanto, são ao mesmo tempo portadores de relações sociais determinadas, nas quais os individuos entram no processo de reprodução de sua vida. Aquelas condições, assim como essas relação, são, por um lado, pressupostos e, por outro, resultados e criações do processo de produção capitalista; são por ele produzidos e reproduzidos" (Marx, 1986, p.272).
\end{abstract}

A produção sempre corresponde a um processo levado a termo por individuos em sociedade, quer pela co-participação que deles se exige, quer pela vigência destas ou daquelas relações sociais que, no caso capitalista, são fundamentalmente as da propriedade privada dos meios de produção e a do regime de trabalho assalariado. $\mathrm{E}$ isto é decisivo. A própria possibilidade do 
homem individualizar-se inscreve-se nos marcos da sociabilidade capitalista, que converte os agentes da produção em seres capazes de atos de vontade, ou seja, converte-os em pólos que se encontram no mercado na condição, meramente formal (legal), de igualdade jurídica. Mas isto supõe relações capitalistas de produção:

"Individuos que produzem em sociedade, ou seja a produção dos individuos socialmente determinada: este é naturalmente o ponto de partida. O caçador ou o pescador isolado e individual, com os que começam Smith e Ricardo, pertencem às imaginações desprovidas de fantasia que produzirão as robinsonadas do século XVIII (...). Quanto mais distantes nos remontamos na bistória, tanto mais aparece 0 individuo - e por conseguinte também o individuo produtor - como dependente e formando parte de um todo maior: em primeiro lugar e de uma maneira todavia inteiramente natural, da familia e dessa família ampliada que é a tribo; mais tarde, das comunidades em suas distintas formas, resultado do antagonismo e da fusão das tribos. Somente ao chegar ao século XVIII, com a 'sociedade civil', as diferentes formas de conexão social aparecem diante do individuo como um simples meio para conseguir seus objetivos particulares, como necessidade exterior. Mas a época que gera este ponto de partida, esta idéia do individuo isolado, é precisamente aquela na qual as relações sociais (universais segundo este ponto de vista) chegaram ao mais alto grau de desenvolvimento alcançado até o presente. O homem é, no sentido mais literal, não apenas um animal social, mas um animal que somente pode individualizar-se em sociedade. A produção por parte do individuo isolado, fora da sociedade - fato raro que bem pode ocorrer quando um civilizado, que potencialmente possui já em si as forças da sociedade, se perde acidentalmente em uma região selvagem - não é menos absurda que a idéia de um desenvolvimento da linguagem sem individuos que vivam juntos $e$ falem entre si (...). Por isto, quando se fala de produção, se está falando sempre de produção em um estágio determinado de desenvolvimento social, da produção de individuos em sociedade" (Marx, 1987, p.3-5). 
Em passagem conhecida de O Capital, Marx busca estabelecer diferenças entre o processo de produzir e o processo de produzir sob a lógica capitalista, ou seja, o processo de produzir mais-valia, fixando negativamente, assim, as particularidades capitalistas, decorrentes das suas relações sociais de produção:

"A produção de valores-de-uso não muda sua natureza geral por ser levada a cabo em beneficio do capitalista ou estar sob seu controle. Por isso, temos inicialmente de considerar o processo de trabalho à parte de qualquer estrutura social determinada. Antes de tudo, o trabalbo é um processo de que participam o bomem e a natureza, processo em que o ser bumano com sua própria ação impulsiona, regula e controla seu intercâmbio material com a natureza (...). Pressupomos o trabalbo sob forma exclusivamente humana. Uma aranba executa operações semelhantes às do tecelão, e a abelha supera mais de um arquiteto ao construir sua colmeia. Mas o que distingue o pior arquiteto da melhor abelha é que ele figura na mente sua construção antes de transformá-la em realidade. No fim do processo do trabalho aparece um resultado que já existia antes idealmente na imaginação do trabalhador. Ele não transforma apenas o material sobre o qual opera; ele imprime ao material o projeto que tinha conscientemente em mira, o qual constitui a lei determinante do seu modo de operar e ao qual tem de subordinar sua vontade (...). O processo de trabalho, que descrevemos em seus elementos simples e abstratos, é atividade dirigida com o fim de criar valores-de-uso, de apropriar os elementos naturais às necessidades humanas; é condição necessária do intercâmbio material entre $o$ homem e a natureza; é condição natural eterna da vida bumana, sem depender, portanto de qualquer forma dessa vida, sendo antes comum a todas as suas formas sociais" (1985, p.201-208).

Ao apontar para os elementos simples do processo de produzir (meios de produção, a força de trabalho e o próprio processo de trabalho), Marx está indicando a desnecessidade da modalidade burguesa de propriedade, o que significa afirmar que as classes proprietárias, elas mesmas, são 
desnecessárias rigorosamente. Mais adiante voltaremos a enfocar a assertiva marxiana segundo a qual o trabalho é condição necessária, natural e eterna da vida humana, independentemente da formação social em que se dá.

Interessa-nos, agora, explicitar um primeiro argumento contrário à tese de fim da sociedade do trabalho. Trata-se de saber se nossa sociedade deixou de ser uma sociedade do trabalho abstrato, dimensão quantitativa do trabalho, que designa a atividade do labour $^{3}$. Em uma palavra, nossa sociedade se estrutura ou não a partir do valor-de-troca? À mercantilização de bens e serviços corresponde ou não uma aspiral ascendente de reificação da totalidade social? As esferas política, jurídica, cultural, por exemplo, estão ou não geneticamente determinadas pela reificação?

A produção de valor-de-uso, de coisas socialmente úteis, pelo intercâmbio com a natureza, isto é, o trabalho enquanto processo produtivo, é um caráter do trabalho social. Mas este também possui um outro caráter, o de ser momento privilegiado de formação. O modo no qual se produz forma, molda, a totalidade social, seja na direção da autorealização humana (emancipação), seja naquela caracterizada em Marx, em Lukács e na primeira geração da Escola de Frankfurt (principalmente Adorno, Horkheimer e Marcuse) pela categoria reificasão:

"Assim como o sistema capitalista se produz e reproduz
economicamente a uma escala cada vez mais alargada, também, no
decurso da evoluşão do capitalismo, a estrutura da reificasăäo penetra
cada vez mais profundamente, fatalmente, constitutivamente na
consciência dos homens. (...) A metamorfose da relagãa mercantil em
coisa dotada de uma 'objetividade fantástica' não pode, pois, limitar-se

${ }^{3}$ Labour, segundo Agnes Heller (1977, p.119-127), expressa o trabalho estranhado, alienado, enquanto work refere-se ao trabalho que produz valor-de-uso, que vale pela sua dimensão concreta. Obviamente, no capitalismo o processo deve ser, a um tempo, produtor de valor-de-uso e de valor-de-troca (dois fatores da mercadoria), onde aquele está subordinado a este, sendo apenas e tão somente o seu veículo.

Temáticas, Campinas, 5(9/10):3-22, jan./dez. 1997 
à transformação em mercadorias de todos os objetos destinados à satisfação de necessidades. Imprime a sua estrutura a toda a consciência do homem; $e$ as propriedades e faculdades desta consciência não estão ligadas somente à unidade orgânica da pessoa, aparecem como 'coisas' que o bomem 'possui' e 'exterioriza', tal como os diversos objetos do mundo exterior. E não bá, em conformidade com a natureza, qualquer forma de relação dos homens entre si, qualquer possibilidade para o bomem de fazer valer as suas 'propriedades' físicas e psicológicas, que não esteja submetida a esta forma de objetividade" (Lukács, 1989, p.108-115).

Assumindo como válida a análise de Lukács, é imperativo dizer que o domínio do capital nunca foi tão presente quanto nos dias atuais. $O$ mundo criado à imagem e semelhança da burguesia é, precisamente, aquele em que a mercantilização se intensificou (em profundidade e amplitude) e, conseqüentemente, a reificação impregnou as diversas esferas da vida social e mesmo privada. A supremacia do capital é a predominância do regime de trabalho assalariado, vale dizer, corresponde à universalização do aviltamento da força de trabalho à condição de mercadoria. $O$ que temos, antes, é a reiteração da exploração do trabalho vivo como a base para o crescimento do capital em valores reais.

O incremento tecnológico ensejado a partir de meados dos anos 70, aliado ao que vem sendo chamado de toyotismo ${ }^{4}$, tem propiciado, no interior da lógica capitalista, uma taxa decrescente de uso. $O$ imperativo da lucratividade se realiza tanto mais quanto bens e serviços forem precocemente consumidos. É a isto que Mészáros (1989) chama de sociedade descartável, onde as três dimensões fundamentais da produção capitalista são profundamente afetadas da seguinte forma:

${ }^{4}$ Cf., a respeito, CORIAT, B., Pensar pelo avesso - O Modelo Japonês de Trabalho e Organização, Rio de Janeiro: Revan : UFRJ, 1994. 
- bens e serviços devem ser consumidos muito velozmente, como descartáveis;

- instalações e maquinaria tornam-se prematuramente obsoletas, mesmo que ainda tenham utilidade social;

- força de trabalho tende a conviver com um desemprego estrutural massivo.

O sistema produtor de mercadorias é, outrossim, dissipador como um todo de recursos naturais. Segmentos dos movimentos em defesa do meio-ambiente podem, eventualmente, se estruturar com uma perspectiva crítica ao capitalismo; todavia, outros segmentos - talvez a maioria articulam-se até mesmo em função de um controle sobre o ritmo em que a natureza é dissipada, sem, contudo, colocar em questão os elementos estruturais de tal fenômeno.

Que outra explicação para a descartabilidade social extremamente abrangente senão à da predominância do valor-de-troca como princípio societário organizador? Como sustentar que a sociedade atual não está mais centrada no trabalho abstrato? Da ótica da emancipação humana até seria bom que já tivéssemos superado a formação social cujo eixo básico é o trabalho abstrato. Todavia, parece que estamos longe disto.

Mas, ao estilo de Gorz, a sociedade contemporânea não enseja a possibilidade de uma sociedade do tempo livre, onde os indivíduos se dedicarão cada vez menos às atividades heterônomas para estarem, cada vez mais, disponíveis àquelas autônomas? Nas palavras do próprio Gorz:

"A industrialização moderna produz uma quantidade enorme de 'tempo livre', e a questão está em discutir o sentido que se deve dar às atividades desenvolvidas neste tempo livre. $O$ sentido possivel para 0 presente é o conceito de uma 'sociedade do tempo livre', em que todos encontram trabalho, mas precisam trabalhar cada vez menos com finalidades econômicas" (1991, p. 313 apud Maar, 1995, p.82). 
Mais adiante, Gorz afirma que

"A lógica do capital, porém, é a única forma de racionalidade econômica pura que existe. Não bá outra forma econômica racional de dirigir um empreendimento além da capitalista (...). Isto não significa que todas as atividades devem se subordinar a esta forma, nem que a racionalidade econômica pura deve predominar. $O$ critério da eficiência exige o maior desempenho por unidade de trabalho, vivo ou morto, isto é, a maximização do lucro. Mas este critério é relevante apenas para uma parte restrita da 'troca com a natureza', (o trabalho instrumental) conforme Marx" (1991, p.150-1, apud Maar, 1995, p.85).

Gorz entende, portanto, que a lógica capitalista não pode ser superada na esfera do trabalho enquanto processo produtivo e que outras atividades podem ser estruturadas independentemente desta. A gaiola de ferro de Weber ganha, aqui, um cadeado inviolável e o canto do pássaro que a habita (a prevalência do valor-de-troca) em nada atinge outros ambientes.

Nada mais ilusório! Inicialmente é preciso dizer que o tempo livre engendrado na sociedade contemporânea não é coletivamente apropriado, a exemplo do que também continua ocorrendo com o resultado da produção capitalista. A redução da jornada de trabalho não se generaliza e tem estado, antes, bem distante de significativas parcelas das classes trabalhadoras, como no caso dos tigres asiáticos, onde se verifica um combinação da forma relativa de extração da mais-valia com extenuantes jornadas de trabalho, situadas entre $12 \mathrm{e}$ 14 horas em setores como têxtil, calçadista e brinquedos, por exemplo. Via de regra, quando há redução da jornada de trabalho, esta vem acompanhada de redução salarial, por vezes endossada pelos próprios sindicatos de trabalhadores, como forma de diminuir os índices de desemprego.

Ou seja, o tempo livre, no balizamento da ordem do capital, não pode ser utilizado senão de forma capitalista, isto é, determinado pela acumulação. Nas palavras de Mészáros: 
"... a adoção generalizada e a utilização criativa do tempo disponivel como o princípio orientador da reprodução societária é, naturalmente, um anátema para o capital, uma vez que não pode ser adaptado à sua estrutura de auto-reprodução expansiva e de valorização (...). Todavia, em contraste total, tempo disponivel, do ponto de vista do capital, é necessariamente percebido ou como algo a ser explorado no interesse da expansão do capital (desde a venda de ferramentas $e$ materiais do tipo 'faça-você-mesmo' à extrema comercialização de toda 'atividade de lazer', seja ela sexo, culto religioso ou arte), ou como vã 'perda de tempo', que como tal não pode ser explorada. (...) $A$ categoria de tempo disponivel, como um princípio orientador, positivo $e$ criativamente utilizável do intercâmbio social, é totalmente incompativel com os interesses da ordem estabelecida" (1989, p.38-9 e 52).

Não é possível aceitar nem o par-de-oposição proposto por Gorz (atividades heterônomas $\mathrm{X}$ atividades autônomas) nem o assumido por Habermas (mundo da vida $\mathrm{X}$ subsistemas, econômico e estatal), pela simples razão - obviamente descartada por estas análises - de que a totalidade social está reificada. Não há esfera social fundamental que esteja isenta da lógica capitalista. O trabalho social, ao contrário do que afirma Gorz, continua tendo o caráter formativo, não se restringindo, portanto, apenas ao aspecto instrumental. No entanto, o trabalho social na formação social capitalista forma e informa a produção e a reprodução da vida produzindo e reproduzindo as relações sociais que lhes são inerentes. A tese do fim da sociedade do trabalho abstrato cumpre uma função ideológica, uma vez que, ao dizer que podem ser organizadas atividades para além da lógica capitalista econômica ${ }^{5}$ (Gorz) ou atividades de interação comunicativa

${ }^{5}$ A rigor, o que existe é a racionalidade capitalista, de forma alguma restrita ao âmbito econômico, uma vez que ela deve ser capaz de plasmar a totalidade social. Não é precisa, portanto, a formulação de Gorz, segundo a qual a racionalidade capitalista é econômica. 
não contaminadas pelos subsistemas econômico e estatal (Habermas), ocultam o núcleo fundamental da totalidade social sob a égide do capital.

O capitalismo somente se reproduz se conseguir naturalizar, eternizar, no plano da subjetividade das classes trabalhadoras as relações sociais capitalistas. Marx apontou para isto quando disse que

\begin{abstract}
"Não basta que haja, de um lado, condições de trabalho sob a forma de capital, e, de outro, seres humanos que nada têm para veñder além de sua força de trabalho. Tampouco basta forçá-los a se venderem livremente. Ao progredir a produção capitalista, desenvolve-se uma classe trabalbadora que por educação, tradição e costume aceita as exigências daquele modo de produção como leis naturais evidentes" (1985, p.854).
\end{abstract}

Assim, do ponto de vista do trabalho abstrato, a sociedade atual continua a se estruturar sob a busca incessante da realização do valor-detroca. A bem da verdade, esta é a mola propulsora da reestruturação produtiva $^{6}$ em curso. Com o escopo de reverter a tendência de queda na taxa de lucro, a ciência e a tecnologia alcançam, hoje mais do que nunca, a condição de força produtiva, hiperdimensinonando uma característica já presente no capitalismo do século XIX:

"Se o processo produtivo torna-se esfera de aplicação da ciência, então... a ciência torna-se um fator, uma função do processo produtivo. Cada descoberta converte-se na base de novos inventos, ou de um novo aperfeiçoamento das formas de produção. $O$ modo capitalista de

\footnotetext{
" O texto de BRAGA, R., "Luta de Classes, Reestruturação Produtiva e Hegemonia", In: KATZ, C.\& outros, Novas Tecnologias - crítica da atual reestruturação produtiva, São Paulo, Xamã, 1995, pp. 45-136, traz uma importante contribuição para esse debate, ao sustentar que a chamada acumulação flexível de capital é uma revolução passiva, em termos gramscianos.
} 
produção coloca desde o inicio as ciências naturais a serviço imediato do processo de produção, ao passo que o desenvolvimento da produção oferece, em troca, os instrumentos para a conquista teórica da natureza. A ciência alcança o reconbecimento de ser um meio de produzir riqueza, um meio de enriquecimento. Desta maneira, os processos produtivos apresentam-se pela primeira vez como problemas práticos, que somente podem ser resolvidos cientificamente. A experiência e a observação (e as necessidades do próprio processo produtivo) alcançam agora, pela primeira vez, um nivel que permite $e$ torna indispensável o emprego da ciência... O desenvolvimento das ciências naturais (que também formam a base de qualquer conhecimento), como o de qualquer noção (que se refira ao processo produtivo) realizam-se, por sua vez, com base na produção capitalista que, pela primeira vez, oferece em ampla medida às ciências os meios materiais de pesquisa, observação e experimentação. Os bomens de ciência, na medida em que as ciências são utilizadas pelo capital como meio de enriquecimento e, portanto, convertem-se elas mesmas em meios de enriquecimento, inclusive para os homens que se ocupam do desenvolvimento da ciência, competem entre si nos intentos de encontrar uma aplicação prática da ciência'"

O colossal crescimento tecnológico atual, em todos os seus ramos, constitui, do ponto de vista das forças produtivas, um pilar cada vez mais importante na acumulação capitalista. Ciência e tecnologia são ainda mais vitais quando o modo de produção capitalista se encontra globalizado. A polivalência exigida sobre trabalhadores altamente qualificados ${ }^{8}$ pode

${ }^{7}$ MARX, K., Progresso Técnico y Desarrollo Capitalista, pp. 191-193, Apud IANNI, O., Teorias da Globalização, p. 156.

${ }^{8}$ Essas características, polivalência e alta qualificação, estão presentes em um segmento relativamente restrito no universo de trabalhadores assalariados. Sobre elas, cf. 
ocultar a natureza da ciência e da tecnologia, enquanto resultado do trabalho vivo, isto é, como expressão de trabalho passado. O saber e o fazer igualmente se subordinam ao acumular. É preciso, assim, superar uma certa fetichização da ciência/tecnologia, pois também elas são engendradas por relações sociais e não podem ser vịstas como autônomas diante das circunstâncias que lhes originaram. Adorno, buscando responder às perguntas sobre como o nazismo foi possível e o que fazer para evitar sua reincidência, chamou a atenção para o risco acima mencionado:

"... no tocante ao consciente coisificado também se deveria observar a sua relação com a técnica, e isso não apenas em grupos pequenos. $A$ relação com a técnica é tão ambígua quanto aquela, aparentada, com $o$ esporte. Por um lado, cada periodo produz aqueles tipos de caráter de que necessita socialmente - os chamados tipos de distribuição psíquica. Um mundo como o atual, em que a tecnologia ocupa posição -chave, produz pessoas tecnológicas, afinadas com a tecnologia. Isso é bem racional: será mais difícil iludi-los, na sua própria área, e isso pode ser transferido para o âmbito mais geral. Por outro lado, a atual atitude para com a tecnologia contém algo de irracional, patológico, exagerado. Isso está relacionado com o 'véu tecnológico'. As pessoas tendem a considerar a tecnologia como algo em si, como fim em si mesmo, como uma força com vida própria, esquecendo-se, porém que se trata do braço prolongado do homem. Os meios - e a tecnologia é a essência para a autopreservação da espécie bumana - são fetichizados, porque as finalidades - uma existência digna do ser bumano - são encobertas e arrancadas do consciente bumano" (Adorno, 1986a, p.41-2)'.

CORIAT, B., op. cit.; LOJKINE, J., $A$ classe operária em mutações, LOJKINE, J., $A$ Revolução Informacional, (principalmente o capítulo XI, A divisão classista em questão).

${ }^{9}$ Sobre o significado de véu ideológico, Adorno sintetizou-o na discussão sobre a impossibilidade de haver alguma dimensão na sociedade capitalista isenta do fenômeno da reificação: "... Já não há lugar fora da engrenagem social a partir do qual se possa 
Voltemos a um aspecto que ficou apenas indicado. Referimo-nos à formulação marxiana segundo a qual o trabalho é a condição natural, necessária e eterna da vida humana. $\mathrm{O}$ que, em nossa perspectiva, Marx quer sublinhar é a impossibilidade do homem prover suas necessidades prescindindo do processo que cria valores-de-uso. $\mathrm{O}$ trabalho, em sua dimensão concreta, é atividade ineliminável da vida social. Porém, a emancipação humana é impensável sem a superação do trabalho estranhado, ou seja, sem a emancipação do trabalho, que inclui, necessariamente, controle coletivo da produção, redução do tempo de trabalho e auto-determinação do processo de trabalho ${ }^{10}$. Não se trata, portanto, do pesado fardo que o homem deve carregar, ao estilo do castigo bíblico imposto aos que comeram o fruto proibido... Esta é condição na qual se encontram as classes trabalhadoras sob a égide do capital. $O$ trabalho como momento privilegiado da auto-realização humana exige a superação, digamos diretamente, da propriedade privada dos meios de produção.

nomear a fantasmagoria; só em sua própria incoerência é que se pode encaixar a alavanca. A isso é o que, há decênios, Horkheimer e eu queríamos nos referir com o conceito de 'véu ideológico'. A falsa identidade entre a organização do mundo e os seus habitantes mediante a total expansão da técnica acaba levando à reafirmação das relações de produção, cujos beneficiários entrementes se procura de modo quase tão frustrante quanto os proletários se tornaram invisiveis" (Adorno, 1986b, p.73-4).

${ }^{10}$ ANTUNES, R., op. cit., p. 81, referindo-se ao processo de emancipação do trabalho, diz que "... a ação efetivamente capaz de possibilitar o salto para além do capital, será aquela que incorpore as reivindicações presentes na cotidianidade do mundo do trabalho, como a redução radical da jornada de trabalho e a busca do 'tempo livre' sob o capitalismo, desde que esta ação esteja indissoluvelmente articulada com o fim da sociedade do trabalbo abstrato e a sua conversão em uma sociedade criadora de coisas verdadeiramente úteis. Este seria o ponto de partida para uma organização societária que caminhe para a realização do reino das necessidades (esfera onde o trabalbo se insere) e deste para o reino da liberdade (esfera onde o trabalho deixa de ser determinado, como disse Marx, pela necessidade e pela utilidade exteriormente imposta)...". 
Todavia, para Marx, trabalho social não é apenas aquele que se dá no processo produtivo, sentido restrito. É práxis social também. Por isto Lukács pôde pensar o trabalho enquanto protoforma da atividade humana, dotada de uma intrínseca posição teleológica, isto é, que se estrutura com vistas a uma finalidade previamente posta:

"Com essas palavras, enuncia-se a categoria ontológica central própria do trabalho: mediante o trabalho, a colocação de uma finalidade no interior do ser material é realizada como formação de uma nova objetividade. Assim, o trabalbo se torna o modelo de toda práxis social, dado que em toda práxis social são sempre realizadas colocasõos de finalidade, de um modo que - em última análise - $e ́$ material, por mais ramificadas que sejam as mediações através das quais isso pode ocorrer. Naturalmente, não é preciso exagerar de modo esquemático esse caráter paradigmático do trabalho para a atuação dos bomens em sociedade; é precisamente ao examinarmos as importantíssimas diferenças que poderemos captar a essencial afinidade ontológica, pois precisamente em tais diferenças deixa-se ver o fato de que o trabalho pode servir como modelo para compreender as outras atividades sociais finalísticas tão-somente na medida em que é a forma ontologicamente originária delas. $O$ simples fato de que 0 trabalho realiza a colocaşão de uma finalidade é uma experiência elementar da vida cotidiana de todos nós: por isso, esse fato tornou-se um componente ineliminável de qualquer pensamento, desde as afirmações cotidianas até a economia e a filosofia" (Lukács, $s / d, p .01)$.

Enquanto protoforma, o trabalho é a atividade originária, fundante, sem a qual outras ficam inviabilizadas, mesmo numa sociedade emancipada. Obviamente, não é a única, nem a mais importante; o que se sublinha, aqui, é a radical inversão que o trabalho não-estranhado, emancipado, deve operar no conjunto das atividades humanas. A auto-determinação implica controle do homem sobre o que faz, ou seja, dimensão teleológica e, neste 
sentido, a humanização do trabalho é condição sine qua non à emancipação humana:

"O fato de ter interpretado o trabalho como forma original da práxis corresponde perfeitamente ao espirito dessa posição de Marx; o próprio Engels, muitas décadas mais tarde, enxergou no trabalbo o motor decisivo do processo de humanização do homem" (Lukács, s/d, p.15).

A práxis social emancipada, em todas as suas manifestações (arte, cultura, política, filosofia, por exemplo), supera em muito a adaptação ao ambiente, o reino da necessidade, o materialismo vulgar e, principalmente, a subalternidade própria das sociedades de classe:

"Apenas no trabalho, na colocação da finalidade e dos meios de sua realização, a consciência, mediante um ato que ela mesmo dirige (ou seja, mediante a colocação da finalidade) ultrapassa a simples adaptação ao ambiente - condição essa que é comum, mesmo àquelas atividades dos animais que transformam objetivamente a natureza de modo involuntário - e põe-se a executar na própria natureza modificações que, para os animais, são impossiveis e até mesmo inconcebiveis. Ora, na medida em que a realização de uma finalidade torna-se um principio transformador e informador da natureza, a consciência que impulsionou e orientou um tal processo não pode ser mais, do ponto de vista ontológico, um epifenômeno. Com essa constatação, o materialismo dialético distingue-se do materialismo mecanicista, que reconbece como realidade objetiva tão somente a natureza em sua legalidade. Marx separa com grande decisão o novo materialismo daquele antigo, ou seja o materialismo dialético do materialismo mecanicista, em suas famosas Teses sobre Feuerbach" (Lukács, $s / d, p .15)^{11}$.

\footnotetext{
${ }^{11}$ A tese sobre Feuerbach em questão é a primeira, de um total de onze: "O principal defeito de todo materialismo até aqui (incluído o de Feuerbach) consiste em que o
} 
Pensamos, com isto, ter logrado duas conclusões:

1) o trabalho concreto (work), enquanto atividade do ser social que dá respostas às suas carências criando valores-de-uso, apresenta caráter ineliminável em qualquer formação social, mesmo naquela que venha a realizar a emancipação humana. Nesta, o trabalho deixa de ser um meio de vida para, efetivamente, aparecer como auto-atividade, protoforma das demais atividades do gênero humano;

2) o capitalismo contemporâneo não só reafirma a prevalência do trabalho abstrato na condição de critério estruturador da totalidade social, como o faz em intensidade elevadíssima e sofisticada. A subordinação do valor-de-uso ao valor-de-troca vigora, na atualidade, sustentada em uma recombinação das formas absoluta e relativa da extração da mais-valia. $O$ sentido último da atual reestruturação produtiva é, precisamente, o de aprofundar a subsunção real do trabalho no capital, através de uma permanente inovação no modo de produção, na produtividade do trabalho e na relação entre capitalista e assalariado. Visa-se, assim, a reprodução das relações sociais estruturantes do capitalismo.

As modificações do capitalismo, neste século, não invalidaram os elementos constitutivos que Marx apontou como tais na sociedade burguesa. E esta contemporaneidade do legado marxiano se explica pela ontologia materialista aí presente, onde o movimento do ser social é apreendido a partir do balizamento no interior da racionalidade capitalista.

objeto, a realidade, a sensibilidade, só é apreendido sob a forma de objeto ou de intuição, mas não como atividade humana sensível, com práxis, não subjetivamente. Eis porque, em oposição ao materialismo, o aspecto ativo foi desenvolvido de maneira abstrata pelo idealismo, que, naturalmente, desconhece a atividade real, sensível, como tal. Feuerbach quer objetos sensiveis - realmente distintos dos objetos do pensamento: mas não apreende a própria atividade humana como atividade objetiva. Por isso, em $\mathrm{A}$ Essência do Cristianismo, considera apenas o comportamento teórico como autenticamente humano, enquanto que a práxis só é apreciada e fixada em sua forma fenomênica judaica e suja. Eis porque não compreende a importância da atividade 'revolucionária', 'prático-crítica'" (Marx \& Engels, 1987, p.11). 
Isto, obviamente, não equivale a sustentar que as condições capitalistas não se alteraram. Todavia, o que se inova não anula os elementos e relações invariantes do modo capitalista de produção.

ABSTRACT: Based on the issue raised by thesis that nowadays work would no longer be a central activity. to social-capitalist formation, this article attempts to examine the validity of social work category as it appears in Marx's thought in order to support, on one hand, the unsurpassable feature of concrete work as a process that generates use-values and, on the other hand, the contemporary continuance of abstract labour logic.

KEYWORDS: Capitalism; Industrial sociology; Labour and labouring classes.

\section{Referências Bibliográficas}

ADORNO, T., "Educação após Auschwitz", In: COHN, G. (org.), Theodor W. Adorno, São Paulo, Ática, 1986a (col. Grandes Cientistas Sociais: 54).

"Capitalismo Tardio ou Sociedade Industrial?", In: COHN, G. (org.), Theodor W. Adorno, São Paulo, Ática, 1986b (col. Grandes Cientistas Sociais: 54).

ANTUNES, R. Adeus ao Trabalbo? - Ensaio sobre as Metamorfoses e a Centralidade do Mundo do Trabalho. São Paulo: Cortez; Campinas: Editora da Unicamp, 1995.

Classe Operária, Sindicatos e Partido no Brasil - da Revolução de 30 até a Aliança Nacional Libertadora. 3 ed. São Paulo, Cortez, 1982.

FREDERICO, C. O Jovem Marx - 1843-44: as origens da ontologia do ser social. São Paulo, Cortez, 1995.

GORZ, A. Adeus ao Proletariado. Rio de Janeiro, Forense, 1982.

Und jetzt Wobin?, Berlin, Rotbuch Verlag, 1991 apud MAAR, W.L., "Fim da Sociedade do Trabalho ou Emancipação Crítica do Trabalho Social?", In: VIGEVANI, T. \& outros. Liberalismo e Socialismo - velhos e novos paradigmas. São Paulo, Editora da Unesp, 1995.

HABERMAS, J., A Nova Intransparência, Novos Estudos Cebrap, São Paulo, 18, setembro de 1987. 
HELLER, A. Sociologia de la Vida Cotidiana. Barcelona, Ed. Península, 1977. IANNI, O. Teorias da globalização, Rio de Janeiro: Civilização Brasileira, 1995. KATZ, C. \& outros. Novas Tecnologias - crítica da atual reestruturação produtiva. São Paulo, Xamã, 1995.

LESSA, S. Lukács e o Marxismo contemporâneo. Temáticas, Campinas, 1(1/2): 95-126. gráfica IFCH/Unicamp, 2o. semestre 1993.

LUKÁCS, G. História e Consciência de Classe - estudos de dialéctica marxista. 2ed. Rio de Janeiro, Elfos Ed.; Porto, Portugal, Publicações Escorpião, 1989.

O trabalho como posição teleológica. trad. Carlos Nelson Coutinho. (trata-se de um capítulo de Ontologia do Ser Socià). 15 p. Mimeografado.

MAAR, W.L. "Fim da Sociedade do Trabalho ou Emancipação Crítica do Trabalho Social?", In: VIGEVANI, T. \& outros. Liberalismo e Socialismo - velhos e novos paradigmas. São Paulo, Editora da Unesp, 1995.

MARX, K. "Trabalho alienado e superação positiva da auto-alienação humana", In: FERNANDES, F. (org.), Marx \& Engels. 3ed. São Paulo, Ática, 1989. (Coleção Grandes Cientistas Sociais: 36). pp. 146-164.

MARX, K. Elementos Fundamentales para la Crítica de la Economía Política Grundrisse 1857-1858. Volume 1. 15 ed. México, Siglo Veintiuno Editores, 1987.

MARX, K. O Capital. Livro 1, volumes I e II. 10 ed. São Paulo, Difusão Editorial S.A., 1985.

MARX, K. O Capital. Livro 3, volume V, 2ed., São Paulo, Nova Cultural, 1986.

MARX, K. \& ENGELS, F. "Teses sobre Feuerbach", In:--- A Ideologia Alemã - I Feuerbach. 6 ed. São Paulo, Hucitec, 1987. p. 11-14.

MARX, K. \& ENGELS, F. "Trabalho Assalariado e Capital", In Obras Escolbidas. volume 1, São Paulo, Alfa-Omega, s/d. p. 52-82.

MÉSZÁROS, I. Produção Destrutiva e Estado Capitalista. São Paulo, Ensaio, 1989. 